\title{
Three Colletotrichum Species, Including a New Species, are Associated to Leaf Anthracnose of Rubber Tree in Hainan, China
}

Xueren Cao, Key Laboratory of Integrated Pest Management on Tropical Crops, Ministry of Agriculture, Environment and Plant Protection Institute, Chinese Academy of Tropical Agricultural Sciences, Haikou 571101, China; Xiangming Xu, NIAB EMR, New Road, East Malling, Kent ME19 6BJ, UK; Haiyan Che, Key Laboratory of Integrated Pest Management on Tropical Crops, Ministry of Agriculture, Environment and Plant Protection Institute, Chinese Academy of Tropical Agricultural Sciences, Haikou 571101, China; Jonathan S. West, Rothamsted Research, Harpenden, AL5 2JQ, UK; and Daquan Luo, ${ }^{\dagger}$ Key Laboratory of Integrated Pest Management on Tropical Crops, Ministry of Agriculture, Environment and Plant Protection Institute, Chinese Academy of Tropical Agricultural Sciences, Haikou 571101, China

\begin{abstract}
Colletotrichum gloeosporioides and C. acutatum have been reported to be causal agents of anthracnose disease of rubber tree. Recent investigations have shown that both C. gloeosporioides and C. acutatum are species complexes. The identities of Colletotrichum species causing anthracnose disease of rubber tree in Hainan, China, are unknown. In this study, 106 isolates obtained from rubber tree with symptoms of anthracnose were collected from 12 counties of Hainan and identified at the species complex level based on the ITS sequences and colony morphologies. Seventy-four isolates were identified as C. gloeosporioides species complex and the other 32 isolates as C. acutatum species complex. Forty-two isolates were selected for further multilocus phylogenetic analyses in order to identify the isolates

to the species level. Twenty-six isolates from the $C$. gloeosporioides species complex were characterized for partial sequences of seven gene regions (ACT, TUB2, CHS-1, GAPDH, ITS, ApMat, and GS), and the other 16 isolates from the $C$. acutatum species complex for five gene regions (ACT, TUB2, CHS-1, GAPDH, and ITS). Three species were identified: $C$. siamense and $C$. fructicola from the $C$. gloeosporioides species complex, and a new species $C$. wanningense from the $C$. acutatum species complex. Artificial inoculation of rubber tree leaves confirmed the pathogenicity of the three species. The present study improves the understanding of species causing anthracnose on rubber tree and provides useful information for the effective control of the disease.
\end{abstract}

Rubber tree (Hevea brasiliensis), a perennial tree of the Euphorbiaceae family, is economically important for production of natural rubber (cis-1,4-polyisoprene), an essential industrial raw material (Leitch et al. 1998; Zou et al. 2009). Although native to the Amazon basin, it is now mainly planted in Southeast Asia, accounting for $97 \%$ of the global supply of natural rubber (Li and Fox 2012). Since the early 1950 s, China has been investing heavily on rubber tree plantation and successfully cultivating rubber trees in the environments perceived to be marginal for rubber trees, mainly in Hainan, Yunnan, and Guangdong provinces (Pu et al. 2007). In China, rubber plantation areas reached nearly one million ha in 2009 with approximately $47 \%$ of the total planting area on Hainan Island (Mo 2010).

Anthracnose of rubber tree leaves is considered as one major cause for the decline in rubber yield in the Asian continent and South American regions (Jayasinghe and Fernando 1998). The disease occurs in the spring and causes leaf necrosis and deformation, and even secondary fall of the youngest leaves when they are infected at the early development stage (Guyot et al. 2001). In China, anthracnose has become a limiting factor for rubber production and may result in significant yield losses (Z. Y. Cai et al. 2009).

${ }^{\dagger}$ Corresponding author: D. Q. Luo, E-mail: Luodaquan@ 163.com

Funding: This work was financially supported by the National Key Research and Development Program of China (2018YFD0201100), the Central Publicinterest Scientific Institution Basal Research Fund for Environment and Plant Protection Institute Chinese Academy of Tropical Agricultural Sciences (hzsjy201708), and the Central Public-interest Scientific Institution Basal Research Fund for Chinese Academy of Tropical Agricultural Sciences (No. 1630042017003).

*The $\boldsymbol{e}$-Xtra logo stands for "electronic extra" and indicates that one supplementary table is published online.

Accepted for publication 8 July 2018.

(c) 2019 The American Phytopathological Society
Morphological, molecular, and fungicide sensitivity studies suggested that $C$. gloeosporioides and $C$. acutatum are causal agents of anthracnose on rubber trees (Brown and Soepena 1994; Saha et al. 2002). In China, C. gloeosporioides was used to be considered as the only anthracnose pathogen. However, C. acutatum has recently been recorded also as a causal agent of anthracnose on rubber trees in Yunnan in 2008 (Zhang et al. 2008) and in Hainan in 2010 (Li et al. 2010).

Both C. gloeosporioides and C. acutatum are species complexes. There are 22 species in addition to one subspecies within the C. gloeosporioides species complex (Weir et al. 2012) and 31 species within the $C$. acutatum species complex (Damm et al. 2012). Recently, several new species were added to the both species complexes. C. acutatum species complex is believed to consist of 34 species and C. gloeosporioides species complex of C. gloeosporioides and 37 other closely related species (Jayawardena et al. 2016b; Marin-Felix et al. 2017).

In addition to $C$. acutatum, several other species (C. citri, $C$. laticiphilum, $C$. nymphaeae, and $C$. simmondsii) were also isolated from rubber trees (Damm et al. 2012; Hunupolagama et al. 2017); all these species belong to the $C$. acutatum species complex. There have been no systematic studies conducted on species related to anthracnose caused by the $C$. gloeosporioides species complex, which is considered to be the dominant species complex in Hainan (Cao et al. 2017). Furthermore, the exact species identities from the $C$. acutatum species complex causing anthracnose of rubber tree in Hainan are unknown. Therefore, this study aimed to identify the Colletotrichum species associated with anthracnose disease of rubber tree in Hainan based on multigene phylogenetic analyses and morphology. The pathogenicity of different Colletotrichum species on rubber tree leaves was then assessed.

\section{Materials and Methods}

Fungal isolation. Rubber tree leaves with anthracnose symptoms were collected from different geographical locations in Hainan, China, from 2015-2017. Three pieces $(5 \times 5 \mathrm{~mm})$ of tissue were taken from the margin of a single anthracnose lesion to isolate the fungus. The leaf pieces were surface sterilized with $70 \%$ ethanol 
for $30 \mathrm{~s}, 1 \% \mathrm{NaClO}$ for $1 \mathrm{~min}$, rinsed in sterile distilled water for $30 \mathrm{~s}$, and finally plated onto potato dextrose agar (PDA). The plates were then incubated at room temperature $\left(28\right.$ to $\left.30^{\circ} \mathrm{C}\right)$ under continuous darkness until fungal colonies had grown. Growing edges of any fungal colony from the tissues were then transferred aseptically to new PDA.

The type specimen of a new species from this study was deposited in the Mycological Herbarium, Institute of Microbiology, Chinese Academy of Sciences, Beijing, China (HMAS), and ex-type living culture deposited in the China General Microbiological Culture Collection Center (CGMCC).

Morphological analysis. Mycelial discs (9 mm diameter) were taken from 5-day-old cultures, plated on PDA, and incubated at $25^{\circ} \mathrm{C}$ in the dark. Daily growth rate was calculated as the 7-day average of mean daily growth ( $\mathrm{mm} /$ day); colony characteristics were recorded. Characteristics of conidial, conidiophores, and appressoria were determined using methods described previously (L. Cai et al. 2009). Appressoria were induced on synthetic nutrient-poor agar (SNA) medium and measured using a slide culture technique (L. Cai et al. 2009). Characteristics of conidia, conidiophores, and appressoria were assessed under a digital microscope (Eclipse 80i, Nikon, Japan).

PCR amplification and DNA sequencing. Isolates were grown on PDA for 7 days at $25^{\circ} \mathrm{C}$ with a 12-h photoperiod. A small amount of aerial mycelium was scraped with a sterile $10 \mu$ pipette tip from the colony surface; genomic DNA was extracted using the E.Z.N.A. Fungal DNA Mini Kit (Omega Bio-tek, Germany) following the manufacturer's instructions. Isolates were identified to the species complex level based on cultural characteristics on PDA, spore morphology, growth rate, and internal transcribed spacer (ITS) sequence.

Forty-two isolates were then selected for taxonomical identification to the species level: 26 and 16 from the $C$. gloeosporioides and $C$. acutatum species complexes, respectively. Isolates of $C$. gloeosporioides species complex were analyzed for partial sequences of seven genomic loci: ITS, actin (ACT), $\beta$-tubulin (TUB2), chitin synthase $1(C H S-1)$, an intron sequence of the glyceraldehyde-3phosphate dehydrogenase $(G A P D H)$, glutamine synthetase $(G S)$, and the mating type locus MAT1-2 (ApMat). These were amplified and sequenced using the primer pairs ITS-1 (Gardes and Bruns 1993) + ITS-4 (White et al. 1990), ACT-512F + ACT-783R (Carbone and Kohn 1999), T1 (O'Donnell and Cigelnik 1997) + Bt2b (Glass and Donaldson 1995), CHS-79F + CHS-354R (Carbone and Kohn 1999), GDF1 + GDR1 (Templeton et al. 1992), GSF1 + GSR1 (Stephenson et al. 1997), and AMF1 + AMR1 (Silva et al. 2012), respectively. Isolates of the $C$. acutatum species complex were analyzed for partial sequences of five loci: ITS, $A C T, T U B 2$, $C H S-1$, and GAPDH.

PCR amplifications were performed with a C1000 thermal cycler (Bio-Rad Laboratories, Hercules, CA) in a $25 \mu$ l reaction volume. The PCR mixtures contained $1 \mu \mathrm{l}$ of DNA template, $12.5 \mu \mathrm{l}$ of TaKaRa Premix Taq (Ex Taq version, TaKaRa, Tokyo, Japan), $1 \mu \mathrm{l}$ of $5 \mu \mathrm{M}$ of each primer. PCR reactions for ITS were performed using the following conditions: initial denaturation at $95^{\circ} \mathrm{C}$ for $4 \mathrm{~min}$, followed by 35 cycles each consisting of $30 \mathrm{~s}$ at $95^{\circ} \mathrm{C}, 30 \mathrm{~s}$ at $52^{\circ} \mathrm{C}$ plus extension for $45 \mathrm{~s}$ at $72^{\circ} \mathrm{C}$, with a final extension step at $72^{\circ} \mathrm{C}$ for $7 \mathrm{~min}$. PCR conditions for other loci were the same except the annealing temperatures: $A C T$ at $58^{\circ} \mathrm{C}, T U B 2$ at $55^{\circ} \mathrm{C}, G A P D H$ at $60^{\circ} \mathrm{C}$, $C H S-1$ at $58^{\circ} \mathrm{C}, G S$ at $60^{\circ} \mathrm{C}$, and ApMat at $62^{\circ} \mathrm{C}$.

PCR products were examined by electrophoresis in $1.5 \%$ agarose gels stained with GoodView Nucleic Acid Stain (Beijing SBS Genetech, Beijing, China) in $1.0 \times$ Tris-acetate acid EDTA (TAE) buffer and photographed under UV light. The PCR products were purified with the Qiangen purification kit (Qiagen, USA) according to the manufacturer's instructions. DNA sequencing was conducted by SinoGenoMax Co., Ltd. (Chinese National Human Genome Center, Beijing, China) with an ABI 3730XL automatic sequencer (Applied Biosystems, USA).

Phylogenetic analysis. The DNA sequences generated with forward and reverse primers were used to obtain consensus sequences using MEGA version 6.0 (Tamura et al. 2013). Multiple sequence alignments were generated using MEGA 6.0 and edited manually if necessary. The consensus sequences were deposited in GenBank (Supplementary Table S1).

Bayesian inference (BI) was used to construct the phylogenetic tree using MrBayes version 3.2.6 (Ronquist et al. 2012). The best evolutionary model for each partition was determined separately according to the corrected Akaike information criterion (AIC) by ModelTest version 3.7 (Posada and Crandall 1998) as implemented in MrMTgui. Markov Chain Monte Carlo (MCMC) analysis with four chains was run twice for 3,000,000 generations, and trees were sampled every 1,000 generations. After omitting the first $25 \%$ of saved trees (burn-in), the remaining sampled trees were used to estimate a $50 \%$ majority rule consensus tree. Clades were regarded as significantly supported if they had a posterior probability $\geq 0.95$ (Ronquist et al. 2012).

Maximum parsimony (MP) analyses based on the multilocus alignment were conducted with PAUP v. $4.0 \mathrm{~b} 10$ (Swofford 2002). Phylogenetic trees were generated using the heuristic search option with tree bisection reconnection (TBR) branch swapping and 1,000 random sequence additions. Maxtrees were unlimited, with branches of zero length collapsed, and all multiple parsimonious trees were saved. Clade stability was assessed using a bootstrap analysis of 1,000 replicates. Tree length (TL), consistency index (CI), retention index (RI), rescaled consistency index (RC), and homoplasy index (HI) were calculated.

An additional maximum likelihood (ML) analysis was carried out with RAxML v. 7.2.6 (Stamatakis 2006) using a GTRGAMMA substitution model with 1,000 bootstrap replicates.

Genealogical concordance phylogenetic species recognition analysis. New species and their most closely related neighbors were analyzed using the genealogical concordance phylogenetic species recognition (GCPSR) model by performing a pairwise homoplasy index (PHI) test (Quaedvlieg et al. 2014). The PHI test was performed in SplitsTree4 (Huson 1998; Huson and Bryant 2006) to determine the recombination level within phylogenetically closely related species using five- or seven-locus concatenated dataset. A PHI value below a 0.05 threshold $\left(\Phi_{\mathrm{W}}<0.05\right)$ indicates the presence of a significant recombination in the dataset. The relationship between closely related species was shown in a split graph.

Pathogenicity assay. Detached rubber tree leaves (Reyan 7-3397, one of the main clones in Hainan, China) were used to confirm pathogenicity of a number of identified Colletotrichum species. Four isolates from $C$. wanningense (Hainan 4, Hainan 5, Hainan 14, Hainan 34) - a new species identified in the present study (see the Results section), three isolates from C. siamense (Hainan 12, Hainan 20, Hainan 22), and one isolate from C. fructicola (Hainan 25) were selected for pathogenicity tests.

Leaves at the light green stage without disease symptoms were wounded by piercing with a sterilized needle. Four wounds on either side of the midrib of each leaf were made. A $10 \mu \mathrm{l}$ droplet of conidial suspension $\left(10^{6}\right.$ conidia $\left.\mathrm{ml}^{-1}\right)$ was placed over every wound; wounds inoculated with sterile water were used as control. Inoculated leaves were placed on a piece of moist tissue paper, incubated in a moist chamber at $25^{\circ} \mathrm{C}$, and assessed daily for lesion development. Lesion diameter at each inoculation site was measured 7 days after inoculation. The experiment followed a completely randomized design with three replicate leaves for each isolate. The experiment was performed twice.

\section{Results}

Collection of Colletotrichum species. In total, 106 Colletotrichum strains were isolated from diseased leaves of rubber trees from 12 cities/counties of Hainan, China. Based on the BLAST search results of the NCBI database with the ITS sequences and the colony morphological characteristics on PDA, all these Colletotrichum strains were initially identified as either the $C$. gloeosporioides species complex (74 isolates) or the $C$. acutatum species complex (32 isolates).

Phylogenetic analyses. Twenty-six isolates in the C. gloeosporioides species complex and 16 isolates in the $C$. acutatum species complex were selected for multilocus phylogenetic analyses on the basis of their geographical location, morphology (colony shape and color and characteristics of aerial mycelia and conidia), and ITS sequences. 
Colletotrichum gloeosporioides species complex. The seven-locus (ACT, TUB2, CHS-1, GAPDH, ITS, ApMat, and GS) phylogenetic analysis of the $C$. gloeosporioides species complex included 75 isolates with $C$. boninense (ICMP 17904) as the outgroup (Fig. 1). The concatenated dataset comprised 4,105 characters including the alignment gaps, of which 703 characters were parsimony informative, 808 parsimony-uninformative, and 2,594 constant. A maximum of 1,000 equally most parsimonious trees were saved (Tree length $=3,019$, $\mathrm{CI}=0.612, \mathrm{RI}=0.756, \mathrm{RC}=0.463$, and $\mathrm{HI}=0.389$ ). For the Bayesian analyses, MrModeltest suggested that ACT, TUB2, GAPDH, ITS, ApMat, and GS partitions should be analyzed with dirichlet state frequency distributions, while the CHS- 1 and ITS partitions should be analyzed with fixed state frequency distributions. The following models recommended by MrModeltest were used: GTR+G for $A C T$ and $G S$, $\mathrm{GTR}+\mathrm{I}$ for $T U B 2, \mathrm{~K} 80+\mathrm{G}$ for $C H S-1, \mathrm{HKY}+\mathrm{I}$ for $G A P D H, \mathrm{SYM}+\mathrm{G}$ for ITS, and HKY+G for ApMat. Bayesian analysis of the combined alignment of the $C$. gloeosporioides species complex was done using 1,841 unique site patterns (ACT: 135, TUB2: 285, CHS-1: 93, GAPDH: 217, ITS: 144, ApMat: 546, and GS: 421). The trees generated from the PAUP and RaxML analyses were similar to that from the Bayesian analysis (Fig. 1). The 26 tested isolates from the $C$. gloeosporioides species complex clustered in two clades. Twenty-five isolates clustered with $C$. siamense, and one isolate with the $C$. fructicola clade.

Colletotrichum acutatum species complex. The five-gene (ACT, TUB2, CHS-1, GAPDH, and ITS) phylogenetic analysis of the
C. acutatum species complex included sequences of 52 isolates with C. orchidophilum (CBS 632.80) as the outgroup (Fig. 2). The concatenated dataset comprised 1,834 characters including the alignment gaps, of which 190 characters were parsimony informative, 211 parsimony-uninformative, and 1,433 constant. A maximum of 1,000 equally most parsimonious trees were saved $(\mathrm{TL}=705, \mathrm{CI}$ $=0.674, \mathrm{RI}=0.821, \mathrm{RC}=0.553$, and $\mathrm{HI}=0.326$ ). For the Bayesian analyses, MrModeltest suggested that ACT, TUB2 and GAPDH, and ITS partitions should be analyzed with dirichlet state frequency distributions, while the $C H S-1$ partition should be analyzed with fixed state frequency distributions. The following models recommended by MrModeltest were used: GTR+G for $A C T, \mathrm{HKY}+\mathrm{G}$ for $T U B 2$ and $G A P D H, \mathrm{~K} 80+\mathrm{I}$ for $C H S-1$, and HKY+I for ITS. The Bayesian analysis of the combined alignment was based on 448 unique site patterns (ACT: 83, TUB2: 122, CHS-1: 43, GAPDH: 126, and ITS: 74). The trees generated from the PAUP and RaxML analyses were similar to that from the Bayesian analysis (Fig. 2). All of the 16 tested isolates from the C. acutatum species complex clustered in the same clade (closely related to $C$. cairnsense), which was distinct from all other known species, and is herein described as a new species in the present study, $C$. wanningense.

Pairwise homoplasy index (PHI) test. Application of the PHI test to the concatenated 5-locus sequences (ITS, ACT, GAPDH, CHS-1, and $T U B 2)$ revealed that no significant recombination event was observed between $C$. wanningense and C. cairnsense $\left(\Phi_{\mathrm{W}}=0.45\right)$. Significant recombination $\left(\Phi_{\mathrm{W}}<0.0001\right)$ was detected among the $26 C$. siamense

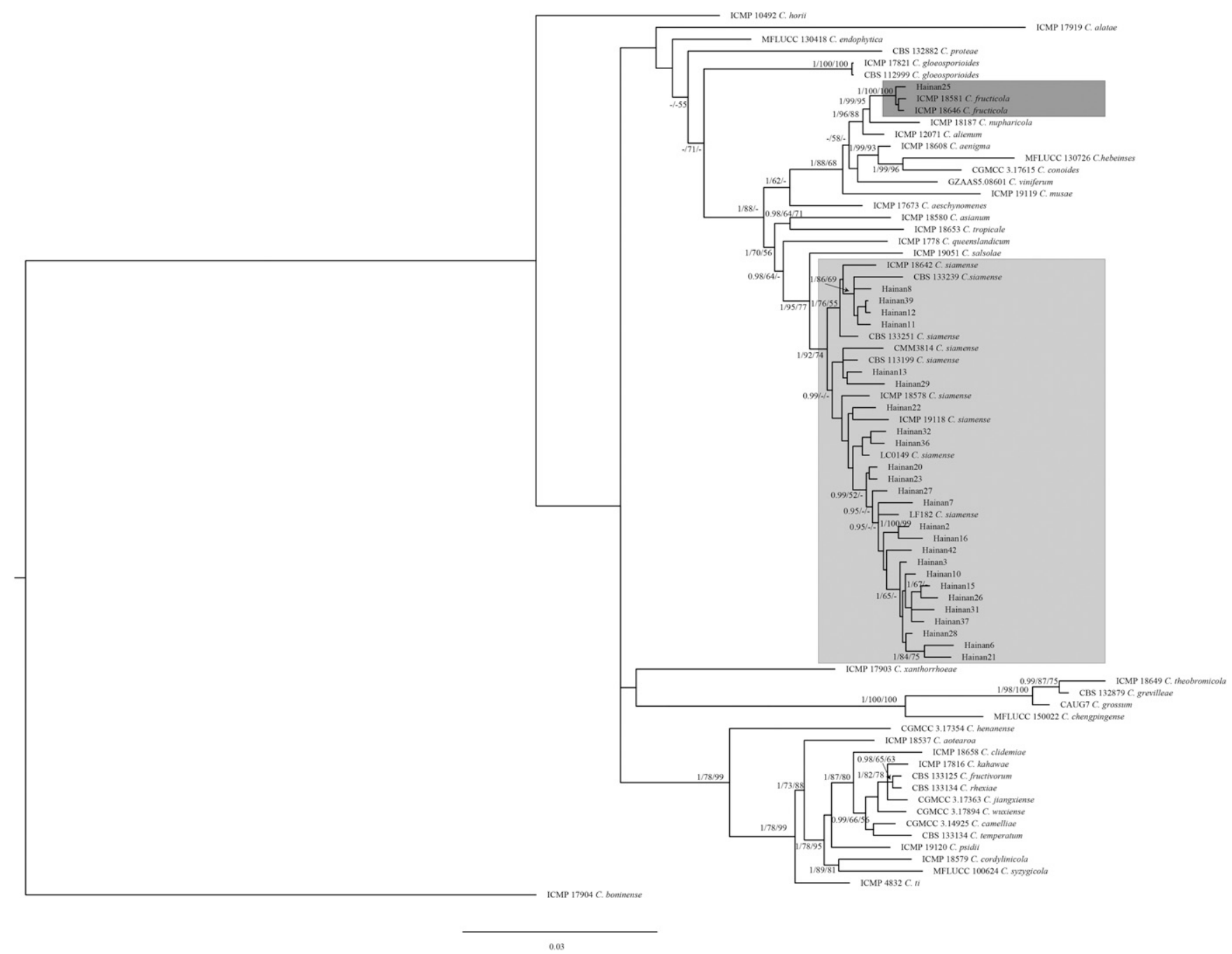

Fig. 1. Phylogenetic consensus tree based on Bayesian inference, illustrating the relationships within the Colletotrichum gloeosporioides species complex of isolates obtained from rubber tree in Hainan, China. The tree was built with Bayesian analysis of concatenated sequences of ACT, TUB2, CHS-1, GAPDH, ITS, ApMat, and GS; the Markov chain was run for $3 \times 10^{6}$ generations, each locus with a separate model of DNA evolution. C. boninense (ICMP 17904) was used as the outgroup. Bayesian posterior probability values $\geq 0.95$, bootstrap support values $\geq 50 \%$, and RAxML bootstrap support values (ML $\geq 50 \%$ ) are shown at the nodes. 
isolates tested in this study and nine $C$. siamense isolates from other studies.

Taxonomy. Based on the morphology and the multilocus phylogeny analysis, 42 Colletotrichum isolates from rubber tree in Hainan are from three species, including one new species: Colletotrichum wanningense X.R. Cao, H.Y. Che \& D.Q. Luo, sp. nov. - MycoBank MB824129 (Fig. 3). Etymology: Referring to the city of Hainan Province in China where the fungus was first collected. Sexual morph was not observed.
Asexual morph on SNA. Vegetative hyphae hyaline, smoothwalled, septate, branched. Chlamydospores not observed. Conidiomata not developed, conidiophores formed directly on hyphae. Setae not observed. Conidiophores hyaline, smooth-walled, septate, branched, 25 to $60 \times 2$ to $4 \mu \mathrm{m}$. Conidiogenous cells hyaline, smooth-walled, cylindrical to ampulliform, 5 to $15 \times 2$ to $4 \mu \mathrm{m}$, apex 1 to $2 \mu \mathrm{m}$ diam. Conidia hyaline, smooth-walled, aseptate, straight, with both ends slightly acute or one end round and one end slightly

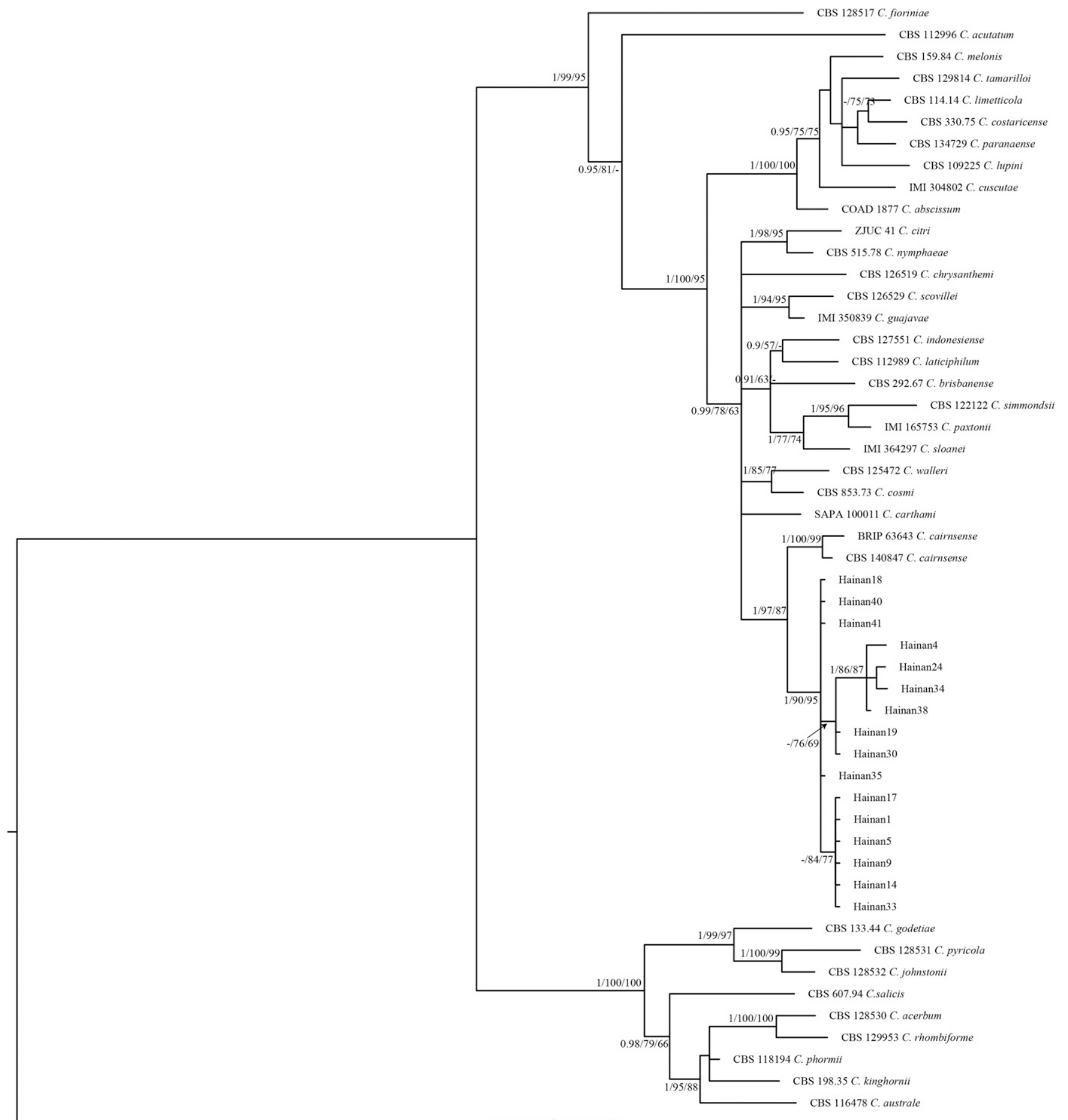

CBS 632.80 C. orchidophilum

Fig. 2. Phylogenetic consensus tree based on Bayesian inference, illustrating the relationships within the Colletotrichum acutatum species complex of isolates obtained from rubbe tree in Hainan, China. The tree was built with Bayesian analysis of concatenated sequences of ACT, TUB2, CHS-1, GAPDH, and ITS; the Markov chain was run for $3 \times 10^{6}$ generations, each locus with a separate model of DNA evolution. C. orchidophillum (CBS 632.80) was used as the outgroup. Bayesian posterior probability values $\geq 0.95$, bootstrap support values $\geq 50 \%$, and RAxML bootstrap support values (ML $\geq 50 \%$ ) are shown at the nodes. 
acute, 7 to $15 \times 2$ to $4 \mu \mathrm{m}$, mean $\pm \mathrm{SD}=10.9 \pm 1.7 \times 3.0 \pm 0.4 \mu \mathrm{m}$, $\mathrm{L} / \mathrm{W}$ ratio $=3.6$. Appressoria solitary, medium to dark brown, smooth-walled, ellipsoidal, clavate to irregular outline, entire edge or undulate, 6 to $15.5 \times 4$ to $8 \mu \mathrm{m}$, mean $\pm \mathrm{SD}=8.9 \pm 1.6 \times 6.2 \pm$ $1.2 \mu \mathrm{m}, \mathrm{L} / \mathrm{W}$ ratio $=1.4$.
Asexual morph on PDA. Colonies on PDA $48 \mathrm{~mm}$ diam. after 7 days at $25^{\circ} \mathrm{C}$ in the dark, with white sparse aerial mycelium and orange conidial masses observed near the inoculum point at both above and reverse; strains Hainan 2, Hainan 9, Hainan 13, and Hainan 15 differ in forming white dense aerial mycelium and reverse white with
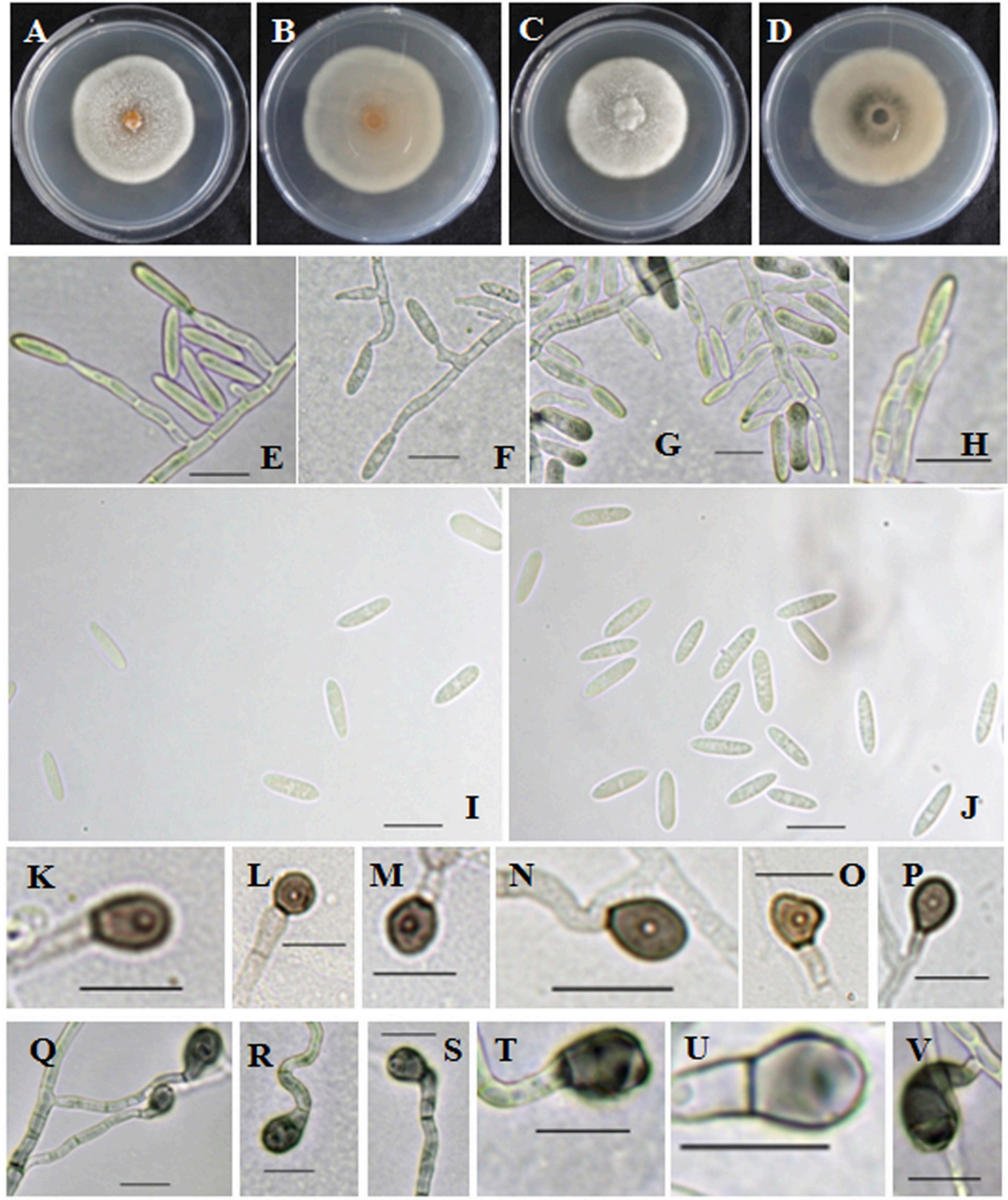

Fig. 3. Culture characteristics and microscopic features of the Colletotrichum wanningense sp. nov. (A-B, E-F, I, K-M, Q-S from ex-holotype strain Hainan 14. C-D, G-H, J, N-P, T-V from strain Hainan 34). A-D, One-week-old colonies on PDA above and below. E-H, Conidiophores. I-J, Conidia. K-P, Appressoria on PDA. Q-V, Appressoria on SNA. Scale bars = $20 \mu \mathrm{m}$. 
brown center surrounded with black. Chlamydospores not observed. Vegetative hyphae hyaline, smooth-walled, septate, branched. Conidiomata and setae not observed. Conidiophores formed directly on aerial mycelium, hyaline, smooth-walled, septate, branched, 20 to $60 \times 2$ to $4 \mu \mathrm{m}$. Conidiogenous cells hyaline, smooth-walled, cylindrical to ampulliform, 8 to $20 \times 1.5$ to $3.5 \mu \mathrm{m}$, apex 1 to $2 \mu \mathrm{m}$ diam. Conidia hyaline, smooth-walled, aseptate, straight, with both ends slightly acute or one end round and one end slightly acute, 7.5 to $12.5 \times 2$ to $4 \mu \mathrm{m}$, mean $\pm \mathrm{SD}=9.8 \pm 1.2 \times 2.9 \pm 0.4 \mu \mathrm{m}, \mathrm{L} / \mathrm{W}$ ratio $=3.4$. Appressoria solitary, medium to dark brown, smooth-walled, ellipsoidal, clavate to irregular outline, entire edge or undulate, 5 to $10.5 \times 4$ to $9 \mu \mathrm{m}$, mean $\pm \mathrm{SD}=$ $7.2 \pm 1.4 \times 5.7 \pm 1.2 \mu \mathrm{m}, \mathrm{L} / \mathrm{W}$ ratio $=1.3$.

Holotype (HMAS 247814): China, Hainan Province, Wanning city, on a living leaf of rubber tree, 1 April 2017, X.R. Cao, extype living culture CGMCC $3.18936=$ Hainan 14 .

Notes: This new species was isolated from infected leaves of rubber tree collected from many counties in Hainan, China; it is phylogenetically most closely related to $C$. cairnsense. Although there is only $1 \mathrm{bp}$ difference between the two species for $A C T, G A P D H$, and ITS, there were 8 bp and 3 bp differences for TUB2 and $C H S$ - 1 , respectively. $C$. wanningense differs in the colony growth rates and spore sizes from $C$. cairnsense: $C$. wanningense has faster growth rates than C. cairnsense ( $48 \mathrm{~mm}$ diam. after 7 days vs. $24 \mathrm{~mm}$ diam. after 7 days) and smaller spores than $C$. cairnsense ( 7.5 to $12.5 \times 2$ to $4 \mu \mathrm{m}$ versus 13 to $15 \times 4 \mu \mathrm{m})$. Colony color differs between the two species: white sparse aerial mycelium (C. wanningense) vs. pale white-gray to olivaceous gray aerial mycelium (C. cairnsense).

Pathogenicity assay. Inoculation of detached wounded leaves at the green stage of rubber trees resulted in typical anthracnose symptoms for all tested Colletotrichum isolates (Fig. 4). Necrotic lesions and typical orange conidial masses were often observed on leaves 5 to 7 days after inoculation. However, there were significant differences in the average lesion diameter between three Colletotrichum species $(P$ $<0.01$ ). Isolates of $C$. siamense and $C$. fructicola resulted in larger necrotic lesions than those caused by $C$. wanningense (Table 1 ).

\section{Discussion}

Identities of Colletotrichum species associated with anthracnose of rubber tree leaves in Hainan, China, were determined using multilocus phylogenetic analyses, and morphological characters; their pathogenicity was confirmed in a detached leaf test. Both TUB2 and $G A P D H$ should be used to differentiate species within the $C$. acutatum species complex (Damm et al. 2012). Liu et al. $(2015,2016)$ used different sets of loci and different phylogenetic analytical methods on a large number of closely related Colletotrichum strains/species from the C. gloeosporioides species complex. They showed that ApMat should be combined with other loci such as $G S$ to achieve satisfactory species delimitation in the $C$. gloeosporioides species complex. ACT, $C H S-1$, and ITS gene regions have been accepted for differentiating species in the $C$. acutatum and $C$. gloeosporioides species complexes (Alvarez et al. 2014; Damm et al. 2012; Jayawardena et al. 2016a; Marin-Felix et al. 2017; Weir et al. 2012). Therefore, five gene regions (ACT, TUB2, CHS-1, GAPDH, and ITS) and seven gene regions (ACT, TUB2, CHS-1, GAPDH, ITS, ApMat, and GS) were selected in this study for classifying isolates into species for the $C$. acutatum and the C. gloeosporioides species complexes, respectively.

C. laticiphilum in the C. acutatum species complex was reported as a causal agent of rubber anthracnose disease in India and Colombia (Damm et al. 2012), while five species (C. acutatum, C. citri, C. laticiphilum, $C$. nymphaeae, and $C$. simmondsii) in the $C$. acutatum species complex were associated with rubber anthracnose disease in Sri Lanka (Hunupolagama et al. 2017). The present study suggested that all the 16 tested isolates from the $C$. acutatum species complex, isolated from rubber tree leaf lesions in Hainan, China, belong to a
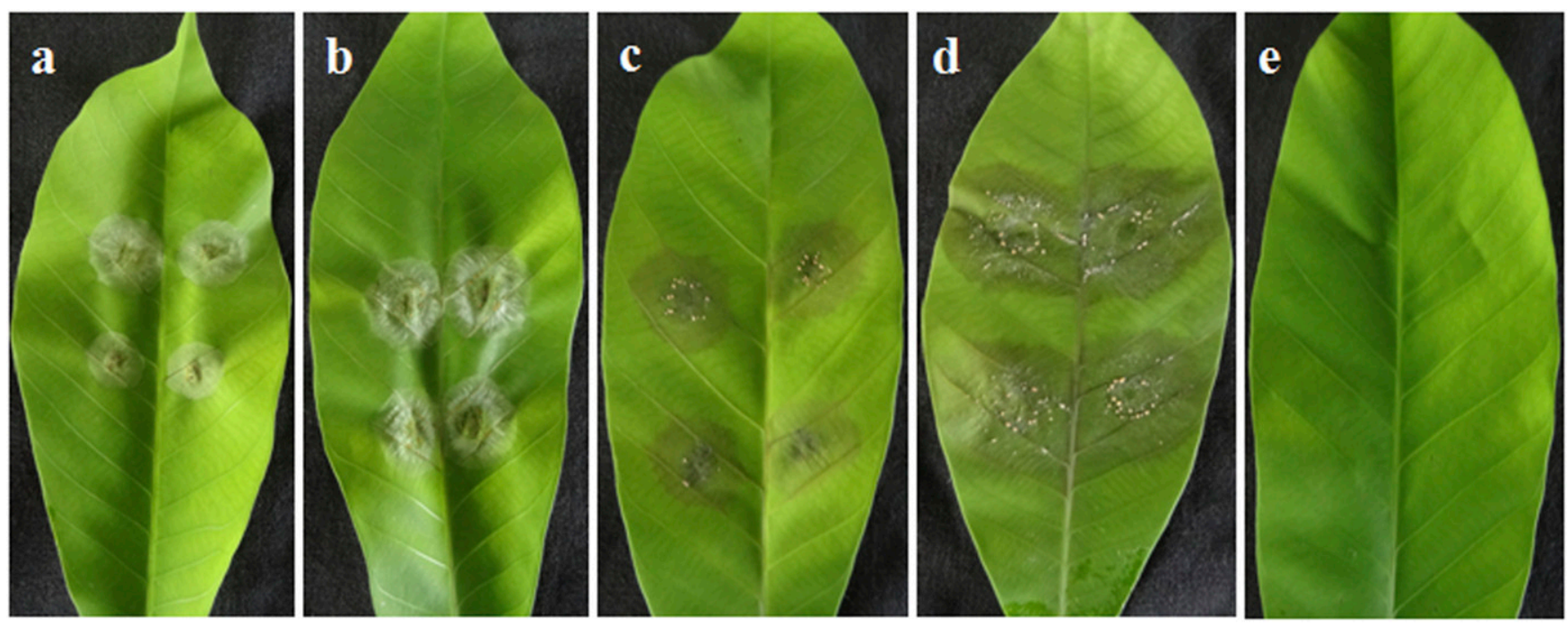

Fig. 4. Pathogenicity assay conducted on detached rubber tree leaves (Reyan 7-33-97) and the symptoms caused by C. wanningense (a, Hainan 14; b, Hainan 34), C. fructicola (c, Hainan 25), C. siamense (d, Hainan 20), and the control inoculated with water (e), 7 days after inoculation at $25^{\circ} \mathrm{C}$.

Table 1. Lesion diameter of Colletotrichum isolates on rubber tree leaves and colony growth rates

\begin{tabular}{|c|c|c|c|c|c|}
\hline \multirow[b]{2}{*}{ Species } & \multirow[b]{2}{*}{ Isolates } & \multicolumn{2}{|c|}{ Lesion diameter $(\mathbf{c m})$} & \multicolumn{2}{|c|}{ Growth rate $(\mathrm{mm} /$ day $)$} \\
\hline & & Mean & Standard deviation & Mean & Standard deviation \\
\hline \multirow[t]{3}{*}{ C. siamense } & Hainan 12 & 1.92 & 0.12 & 11.33 & 0.23 \\
\hline & Hainan 20 & 1.89 & 0.13 & 10.93 & 0.31 \\
\hline & Hainan 22 & 1.10 & 0.12 & 11.20 & 0.20 \\
\hline C. fructicola & Hainan 25 & 1.83 & 0.32 & 10.80 & 0.35 \\
\hline \multirow[t]{4}{*}{ C. wanningense } & Hainan 4 & 1.23 & 0.14 & 7.33 & 0.31 \\
\hline & Hainan 5 & 1.33 & 0.18 & 6.67 & 0.12 \\
\hline & Hainan 14 & 1.17 & 0.12 & 7.20 & 0.20 \\
\hline & Hainan 34 & 1.19 & 0.18 & 7.40 & 0.40 \\
\hline
\end{tabular}


new species, here named as $C$. wanningense. $C$. acutatum species complex was identified as the main cause associated with rubber tree in Sri Lanka (Jayasinghe et al. 1997), whereas it was first reported in Hainan in 2010 (Li et al. 2010).

A polyphasic approach, including geographical, ecological, morphological, and genetic data, is currently recommended to establish a natural classification system for the genus Colletotrichum (L. Cai et al. 2009). For species delimitation within this genus, phylogenetic analysis based on concatenated loci and genealogical concordance phylogenetic species recognition (GCPSR) has proven to be powerful tools (Cannon et al. 2012; Liu et al. 2016). GCPSR suggested that the absence of recombination between $C$. wanningense and its most closely related species $C$. cairnsense.

Both $C$. siamense and $C$. fructicola were originally described as causal agents of anthracnose on coffee berries in northern Thailand (Prihastuti et al. 2009). These two species are cosmopolitan and have diverse host species (Doyle et al. 2013; Liu et al. 2016; Schena et al. 2014; Sharma et al. 2015; Udayanga et al. 2013; Vieira et al. 2014; Weir et al. 2012). In Hainan, both C. siamense and C. fructicola were reported on Camellia oleifera, Santalum album, Pueraria lobata, Alchornea davidii, Symplocos sumuntia, Maesa perlarius, and Livistona chinensis (Jiang et al. 2016; Li et al. 2016). Additionally, C. siamense was reported on Khaya senegalensis, Mangifera indica, and Bauhinia purpurea whereas C. fructicola was reported on Aporosa chinensis, Alchornea davidii, and Dalbergia odorifera (Jiang et al. 2016; Li et al. 2016). This report demonstrates that both species can infect leaves of rubber trees in Hainan and that $C$. siamense is the most prevalent species in the $C$. gloeosporioides species complex that causes leaf anthracnose of rubber tree in Hainan. Generally, isolates of $C$. siamense and $C$. fructicola caused larger necrotic lesions than those caused by $C$. wanningense, consistent with a previous report that $C$. acutatum has a lower level of pathogenicity than C. gloeosporioides (Jayasinghe et al. 2009).

C. siamense was considered as a species complex (Sharma et al. 2015; Udayanga et al. 2013; Vieira et al. 2014), but this has been rejected recently (Liu et al. 2016). The present study also indicated significant recombination among the $35 \mathrm{C}$. siamense isolates, suggesting that $C$. siamense is unlikely to be a species complex.

In summary, we have identified three Colletotrichum species, $C$. siamense and $C$. fructicola from the $C$. gloeosporioides species complex and a new species (C. wanningense) from the $C$. acutatum species complex, as causal agents of anthracnose on rubber tree leaves in Hainan, China. For effective disease management, further research is necessary to understand whether these three species differ in their response to climatic conditions, common fungicides, and popular rubber tree genotypes. Such knowledge will help development of more targeted disease management strategies.

\section{Literature Cited}

Álvarez, E., Gañán, L., Rojas, A., Mejía, J. F., Llano, G. A., and González, A. 2014. Diversity and pathogenicity of Colletotrichum species isolated from Soursop in Colombia. Eur. J. Plant Pathol. 139:325-338.

Brown, A., and Soepena, H. 1994. Pathogenicity of Colletotrichum acutatum and C. gloeosporioides on leaves of Hevea spp. Mycol. Res. 98:264-266.

Cai, L., Hyde, K. D., Taylor, P. W. J., Weir, B., Waller, J. M., Abang, M. M., Zang, J. C., Yang, Y. L., Phouliyong, S., Prihastuti, Z. Y., Shivas, R. G., McKenzie, E. H. C., and Johnston, P. R. 2009. A polyphasic approach for studying Colletotrichum. Fungal Divers. 39:183-204.

Cai, Z. Y., Li, J. Z., He, M. X., Xiao, C. Y., and Zhang, C. X. 2009. The effect of three hot fogging concentrates on Colletotrichum leaf fall of rubber tree in rubber plantation. Trop Agric. Sci. Technol. 32:10-11.

Cannon, P. F., Damm, U., Johnston, P. R., and Weir, B. S. 2012. Colletotrichum current status and future directions. Stud. Mycol. 73:181-213.

Cao, X. R., Xu, X. M., Che, H. Y., West, J. S., and Luo, D. Q. 2017. Distribution and fungicide sensitivity of Colletotrichum species complexes from rubber tree in Hainan, China. Plant Dis. 101:1774-1780.

Carbone, I., and Kohn, L. M. 1999. A method for designing primer sets for speciation studies in filamentous ascomycetes. Mycologia 91:553-556.

Damm, U., Cannon, P. F., Woudenberg, J. H. C., and Crous, P. W. 2012. The Colletotrichum acutatum species complex. Stud. Mycol. 73:37-113.

Doyle, V. P., Oudemans, P. V., Rehner, S. A., and Litt, A. 2013. Habitat and host indicate lineage identity in Colletotrichum gloeosporioides s. 1. from wild and agricultural landscapes in North America. PLoS One 8:e62394.
Gardes, M., and Bruns, T. D. 1993. ITS primers with enhanced specificity for basidiomycetes - application to the identification of mycorrhizae and rusts. Mol. Ecol. 2:113-118.

Glass, N. L., and Donaldson, G. C. 1995. Development of primer sets designed for use with the PCR to amplify conserved genes from filamentous ascomycetes. Appl. Environ. Microbiol. 61:1323-1330.

Guyot, J., Omanda, E. N., Ndoutoume, A., Otsaghe, A. A. M., Enjalric, F., and Assoumou, H. G. N. 2001. Effect of controlling Colletotrichum leaf fall of rubber tree on epidemic development and rubber production. Crop Prot. 20:581-590.

Hunupolagama, D. M., Chandrasekharan, N. V., Wijesundera, W. S. S. Kathriarachchi, H. S., Fernando, T. H. P. S., and Wijesundera, R. L. C. 2017. Unveiling members of Colletotrichum acutatum species complex causing Colletotrichum leaf disease of Hevea brasiliensis in Sri Lanka. Curr. Microbiol. 74:747-756.

Huson, D. H. 1998. SplitsTree: analyzing and visualizing evolutionary data. Bioinformatics 14:68-73.

Huson, D. H., and Bryant, D. 2006. Application of phylogenetic networks in evolutionary studies. Mol. Biol. Evol. 23:254-267.

Jayasinghe, C. K., and Fernando, T. H. P. S. 1998. Growth at different temperatures and on fungicide amended media: two characteristics to distinguish Colletotrichum species pathogenic to rubber. Mycopathologia 143:93-95.

Jayasinghe, C. K., Fernando, T. H. P. S., and Jayawardana, N. 2009. A comparative study of Colletotrichum species causing anthracnose in Hevea. J. Rubber Res. Inst. Sri Lanka 89:20-32.

Jayasinghe, C. K., Fernando, T. H. P. S., and Priyanka, U. M. S. 1997 Colletotrichum acutatum is the main cause of Colletotrichum leaf disease of rubber in Sri Lanka. Mycopathologia 137:53-56.

Jayawardena, R. S., Huang, J. K., Jin, B. C., Yan, J. Y., Li, X. H., Hyde, K. D., Bahkali, A. H., Yin, S. L., and Zhang, G. Z. 2016a. An account of Colletotrichum species associated with strawberry anthracnose in China based on morphology and molecular data. Mycosphere 7:1147-1163.

Jayawardena, R. S., Hyde, K. D., Damm, U., Cai, L., Liu, M., Li, X. H., Zhang, W., Zhao, W. S., and Yan, J. Y. 2016b. Notes on currently accepted species of Colletotrichum. Mycosphere 7:1192-1260.

Jiang, S. Q., Li, Y., Zhou, G. Y., Liu, J., Wan, Z., Jiang, Y. X., and Li, H. 2016. Population genetic structure of Colletotrichum siamense from four sites in Hainan province. Chin. J. Trop. Crops. 37:2204-2209.

Leitch, A. R., Lim, K. Y., Leitch, I. J., O’Neill, M., Chye, M. L., and Low, F. C. 1998. Molecular cytogenetic studies in rubber, Hevea brasiliensis Muell. Arg. (Euphorbiaceae). Genome 41:464-467.

Li, H., Li, Y., Xu, J. P., and Zhou, G. Y. 2016. Population genetic structure of Colletotrichum fructicola from oil- tea and other host plants in Hainan province. Sci. Silvae Sin. 52:80-88

Li, J. F., Liu, X. B., Cai, J. M., Lin, C. H., and Huang, G. X. 2010. Identification and the internal transcribed spacer regions analysis of pathogen causing rubber anthracnose. Chin. Agric. Sci. Bull. 26:221-226.

Li, Z., and Fox, J. M. 2012. Mapping rubber tree growth in mainland Southeast Asia using time-series MODIS $250 \mathrm{~m}$ NDVI and statistical data. Appl. Geogr. 32:420-432.

Liu, F., Wang, M., Damm, U., Crous, P. W., and Cai, L. 2016. Species boundaries in plant pathogenic fungi: a Colletotrichum case study. BMC Evol. Biol. 16:81.

Liu, F., Weir, B. S., Damm, U., Crous, P. W., Wang, Y., Liu, B., Wang, M., Zhang, M., and Cai, L. 2015. Unravelling Colletotrichum species associated with camellia: employing ApMat and GS loci to resolve species in the C. gloeosporioides complex. Persoonia 35:63-86.

Marin-Felix, Y., Groenewald, J. Z., Cai, L., Chen, Q., Marincowitz, S., Barnes, I., Bensch, K., Braun, U., Camporesi, E., Damm, U., De Beer, Z. W., Dissanayake, A., Edwards, J., Giraldo, A., Hernández-Restrepo, M., Hyde, K. D., Jayawardena, R. S., Lombard, L., Luangsa-ard, J., McTaggart, A. R., Rossman, A. Y., Sandoval-Denis, M., Shen, M., Shivas, R. G., Tan, Y. P., van der Linde, E. J., Wingfield, M. J., Wood, A. R., Zhang, J. Q., Zhang, Y., and Crous, P. W. 2017. Genera of phytopathogenic fungi: GOPHY 1. Stud. Mycol. 86:99-216.

Mo, Y. 2010. Production and marketing situation of nature rubber in 2009 and market prediction for 2010. China Trop. Agric. 7:12-15.

O'Donnell, K., and Cigelnik, E. 1997. Two divergent intragenomic rDNA ITS2 types within a monophyletic lineage of the fungus Fusarium are nonorthologous. Mol. Phylogenet. Evol. 7:103-116.

Posada, D., and Crandall, K. A. 1998. Modeltest: testing the model of DNA substitution. Bioinformatics 14:817-818.

Prihastuti, H., Cai, L., Chen, H., Mckenzie, E. H. C., and Hyde, K. D. 2009. Characterization of Colletotrichum species associated with coffee berries in northern Thailand. Fungal Divers. 39:89-109.

Pu, J. J., Zhang, X., Qi, Y. X., Xie, Y. X., Zhang, H. Q., and Zhang, H. 2007. First record of Corynespora leaf fall disease of Hevea rubber tree in China. Australas. Plant Dis. Notes 2:35-36.

Quaedvlieg, W., Binder, M., Groenewald, J. Z., Summerell, B. A., Carnegie, A. J., Burgess, T. I., and Crous, P. W. 2014. Introducing the consolidated species concept to resolve species in the Teratosphaeriaceae. Persoonia 33:1-40.

Ronquist, F., Teslenko, M., van der Mark, P., Ayres, D. L., Darling, A., Höhna, S., Larget, B., Liu, L., Suchard, M. A., and Huelsenbeck, J. P. 2012. MrBayes 3.2: 
efficient Bayesian phylogenetic inference and model choice across a large model space. Syst. Biol. 61:539-542.

Saha, T., Kumar, A., Ravindran, M., Jacob, C. K., Bindu, R. O. Y., and Nazeer, M. A. 2002. Identification of Colletotrichum acutatum from rubber using random amplified polymorphic DNAs and ribosomal DNA polymorphisms. Mycol. Res. 106:215-221.

Sharma, G., Pinnaka, A. K., and Belle, D. S. 2015. Resolving the Colletotrichum siamense species complex using ApMat marker. Fungal Divers. 71:247-264.

Schena, L., Mosca, S., Cacciola, S. O., Faedda, R., Sanzani, S. M., Agosteo, G. E., Sergeeva, V., and Magnano di San Lio, G. 2014. Species of the Colletotrichum gloeosporioides and $C$. boninense complexes associated with olive anthracnose. Plant Pathol. 63:437-446.

Silva, D. N., Talhinhas, P., Várzea, V., Cai, L., Paulo, O. S., and Batista, D. 2012. Application of the Apn2/MAT locus to improve the systematics of the Colletotrichum gloeosporioides complex: an example from coffee (Coffea spp.) hosts. Mycologia 104:396-409.

Stamatakis, A. 2006. RAxML-VI-HPC: maximum likelihood-based phylogenetic analyses with thousands of taxa and mixed models. Bioinformatic 22:2688-2690.

Stephenson, S. A., Green, J. R., Manners, J. M., and Maclean, D. J. 1997. Cloning and characterisation of glutamine synthetase from Colletotrichum gloeosporioides and demonstration of elevated expression during pathogenesis on Stylosanthes guianensis. Curr. Genet. 31:447-454.

Swofford, D. L. 2002. Phylogenetic analysis using parsimony. Sinauer Associates Inc, software, Sunderland, MA.
Tamura, K., Stecher, G., Peterson, D., Filipski, A., and Kumar, S. 2013. MEGA6: molecular evolutionary genetics analysis version 6.0. Mol. Biol. Evol. 30:2725-2729.

Templeton, M. D., Rikkerink, E. H., Solon, S. L., and Crowhurst, R. N. 1992 Cloning and molecular characterization of the glyceraldehyde-3-phosphate dehydrogenase-encoding gene and cDNA from the plant pathogenic fungus Glomerella cingulata. Gene 122:225-230.

Udayanga, D., Manamgoda, D. S., Liu, X., Chukeatirote, E., and Hyde, K. D. 2013. What are the common anthracnose pathogens of tropical fruits? Fungal Divers. 61:165-179.

Vieira, W. A. S., Michereff, S. J., de Morais, M. A., Jr., Hyde, K. D., and Câmara M. P. S. 2014. Endophytic species of Colletotrichum associated with mango in northeastern Brazil. Fungal Divers. 67:181-202.

Weir, B. S., Johnston, P. R., and Damm, U. 2012. The Colletotrichum gloeosporioides species complex. Stud. Mycol. 73:115-180.

White, T. J., Bruns, T., Lee, S., and Taylor, J. 1990. Amplification and direct sequencing of fungal ribosomal RNA genes for phylogenetics. Pages 315-322 in: PCR Protocols: A Guide to Methods and Applications. M. A. Innis, D. H. Gelfand, and J. J. Sninsky, eds. Academic Press, San Diego, CA.

Zhang, C. X., He, M. X., Li, J. Z., Cai, Z. Y., and Wang, J. Q. 2008. Identification of the pathogen causing Colletotrichum leaf disease on rubber in Xishuangbanna Yunnan. Plant Prot. 34:103-106.

Zou, Z., Yang, L. F., Wang, Z. H., and Yuan, K. 2009. Biosynthesis and regulation of natural rubber in Hevea. Plant Physiol J. 45:1231-1238. 